\section{RSP}

http://www.rsp.fsp.usp.br/
Revista de Saúde Pública

\title{
Burden of ischemic heart disease mortality attributable to physical inactivity in Brazil
}

\author{
Diego Augusto Santos Silva', Deborah Carvalho Malta", Maria de Fatima Marinho de Souza"I, \\ Mohsen Naghavi"
}

I Universidade Federal de Santa Catarina. Núcleo de Pesquisa em Cineantropometria e Desempenho Humano. Florianópolis, SC, Brasil

" Universidade Federal de Minas Gerais. Escola de Enfermagem. Departamento de Enfermagem Materno-Infantil e Saúde Pública. Belo Horizonte, MG, Brasil

III Ministério da Saúde. Departamento de Vigilância de Doenças e Agravos Não Transmissíveis e Promoção da Saúde. Brasília, DF, Brasil

Iv University of Washington. Institute for Health Metrics and Evaluation. Seattle, WA, United States

\section{ABSTRACT}

OBJECTIVE: To analyze if the burden of ischemic heart disease mortality trend attributed to physical inactivity in Brazil differs from the global estimates.

METHODS: Databases from the Global Burden of Disease Study for Brazil, Brazilian states, and global information were used. We estimated the summary exposure value for physical inactivity, the total number of deaths, and the age-standardized death rates for ischemic heart disease attributed to physical inactivity in the years 1990 and 2015, and the population-attributable fraction. Data were presented according to sex.

RESULTS: The Brazilian population was found to have a risk of exposure to physical inactivity varying between $70.4 \%$ for men and $75.7 \%$ for women in the year of 1990 . This risk of exposure was similar in 2015. In men, the mortality rate from ischemic heart disease attributed to physical inactivity decreased in 2015 by approximately $24 \%$ around the world and $45 \%$ in Brazil. For women, this decrease was in $31 \%$ around the world and $45 \%$ in Brazil. The states of Southern and Southeastern Brazil presented lower mortality rates due to ischemic heart disease attributed to physical inactivity. If physical inactivity were eliminated in Brazil, mortality from ischemic heart disease would be reduced by $15.8 \%$ for men and $15.2 \%$ for women.

CONCLUSIONS: Over 25 years, the risk of exposure to physical inactivity in Brazil did not change and was high compared to global estimates. The decrease in ischemic heart disease mortality results from the improvement of health services in Brazil and the control of other risk factors. Approximately $15 \%$ of deaths from ischemic heart disease in Brazil could be avoided if people met the recommendations for physical activity.

DESCRIPTORS: Sedentary Lifestyle. Global Burden of Disease. Cardiovascular Diseases, mortality. Motor Activity.

\footnotetext{
Souza MFM, Naghavi M. Burden

of ischemic heart disease mortality

attributable to physical inactivity

in Brazil. Rev Saude Publica.

2018;52:72.

Copyright: This is an open-access article distributed under the terms of the Creative Commons Attribution License, which permits unrestricted use, distribution, and reproduction in any medium, provided that the original author

and source are credited.

Diego Augusto Santos Silva

Centro de Desportos

Campus Universitário - Trindade

88040-900 Florianópolis, SC, Brasil

E-mail:diegoaugustoss@yahoo.

Received: Aug 10, 2017

Approved: Dec 22, 2017
} 


\section{INTRODUCTION}

An epidemiological study ${ }^{1}$ evaluated the effects of physical inactivity on the burdens of chronic non-communicable diseases (NCD) worldwide, and they found approximately a $6.0 \%$ disease burden for coronary heart disease, $7.0 \%$ for type 2 diabetes, $10.0 \%$ for breast cancer, and $10.0 \%$ for colon cancer. This theme of attributing the burden of disease to physical activity was introduced into evidence in the early 2000s.

Even with this evidence, the level of physical activity in populations around the world continues to decline, prompting alarm from health services ${ }^{2}$. In Brazil, a 2014 survey of adult men and women from all capital cities showed that $64.7 \%$ of the adult population did not reach the recommended physical activity level ${ }^{3}$. This epidemic of physical inactivity results from several factors, such as the technological development that requires sedentary activities by the population ${ }^{2}$. Sedentary activities cause lower energy expenditure and lower chances of physical activity throughout the day ${ }^{4}$. Another factor that stands out is the growth of cities over the decades. In low- and middle-income countries, such as Brazil, the cities have grown without planning and spaces for promoting physical activity ${ }^{5}$.

Physical inactivity is a risk factor for several NCD (ischemic heart disease, arthritis, type 2 diabetes, some cancers, obesity, and stroke) which present a high burden of morbidity and mortality across the world ${ }^{6}$. Among NCD that have physical inactivity as one of the risk factors, ischemic heart disease stands out because it is responsible for one of the highest mortality rates attributable to cardiovascular diseases in Brazil ${ }^{6}$. In this sense, investigating how this disease with high mortality burden in Brazil is attributable to physical inactivity can help guide public policy.

The independent role of physical activity in the primary prevention of coronary heart diseases, such as ischemic heart disease, is well established and has been assessed in numerous reviews or meta-analyses ${ }^{7,8}$. Although all reviews agree that physical activity is associated with a $20.0 \%$ to $30.0 \%$ lower ischemic heart disease risk, no research has been conducted in Brazil to quantify the burden of mortality due to ischemic heart disease attributable to physical inactivity. This lack of information makes it difficult to monitor existing public policies to promote physical activity.

Brazil is a middle-income country that has recently improved its national health databases and implemented a series of surveys to better assess NCD risk factors, prevalence, and disease burden ${ }^{9}$. The 2015 Global Burden of Disease Study (GBD) has incorporated this more precise information into their internationally standardized approach for characterizing disease burden. Furthermore, to date, Brazil has engaged energetically in the WHO's challenge to confront $\mathrm{NCD}^{10}$.

The aim of this study was to analyze if the trend of the burden of ischemic heart disease mortality attributed to physical inactivity in Brazil differs from the global estimates.

\section{METHODS}

The 2015 GBD includes an annual assessment covering 195 countries and territories from 1990 to 2015. It covers 310 diseases and injuries, 2,619 sequelae, and 79 risk factors by age and sex. Detailed descriptions of the methodology and approach of the 2015 GBD have been published elsewhere ${ }^{11-13}$. In this study, the estimates presented were generated using the visualizations of the Institute for Health Metrics and Evaluation's $2015 \mathrm{GBD}^{14}$.

Cause of death was defined by international standards governing the reporting of death certificates, in which a single underlying cause is assigned by a physician. Ischemic heart disease was defined as an underlying cause of death across International Classification of Diseases (ICD) revisions, most recently in ICD-10 I20 to I25 and ICD-9 410 to $414^{15}$. Ischemic heart disease mortality was considered as the summation of four distinct disease sequelae: 
acute myocardial infarction, chronic stable angina, chronic ischemic heart disease, and heart failure due to ischemic heart disease ${ }^{16}$.

Vital registration, verbal autopsy and surveillance data were used to model ischemic heart disease. For Brazil, information from the Mortality Information System ${ }^{14}$ was used.

Physical activity was measured for adults older than or equal to 25 years of age, for durations of at least ten minutes at a time, across all domains of life (leisure or recreation, work, household, and transport). The frequency, duration, and intensity of activity were used to calculate the total metabolic equivalent (MET) in minutes per week. MET is the ratio of the working metabolic rate to the resting metabolic rate; one MET is equivalent to $1 \mathrm{kcal} / \mathrm{kg} /$ hour and is equal to the energy cost of sitting quietly. A MET is also defined as the oxygen uptake in $\mathrm{ml} / \mathrm{kg} / \mathrm{min}$, with one MET equal to the oxygen cost of sitting quietly, which is approximately $3.5 \mathrm{ml} / \mathrm{kg} / \mathrm{min}^{13}$.

We included surveys of the general adult population, performed using random sampling, that captured self-reported physical activity in all domains of life (leisure or recreation, work, household, and transport). For the global estimates, data were primarily derived from two standardized questionnaires, The Global Physical Activity Questionnaire and the International Physical Activity Questionnaire, although any other survey instrument that asked about the intensity, frequency, and duration of physical activities performed across all activity domains ${ }^{13}$ was included. For Brazil ${ }^{17}$, we consulted existing surveys such the Surveillance System for Risk and Protective Factors for Chronic Diseases by Telephone Survey (VIGITEL), Brazil World Health Survey, and the International Prevalence Study on Physical Activity. Due to the absence of a consistent relationship, on the individual level, between the amount of activity performed in each domain and total activity, it was not possible to use studies that included only recreational/leisure activities ${ }^{13}$. The physical activity level was categorized by total MET-minutes per week and the estimates were made for the subjects classified as inactive $(<600 \text { METS-min/week })^{18}$.

The contribution of physical inactivity to the mortality by ischemic heart disease was estimated using a comparative risk assessment approach in which observed health outcomes are compared to those that would have been observed with a counterfactual set of exposure where no one is exposed ${ }^{13}$. For this, we used the Cause of Death Ensemble Modeling-CODEm (CODEm) that is used to estimate indicators by age, sex, country, year, and cause, and is an analytical tool that tests several possible statistical models of causes of death and creates a combined set of models that offers the best predictive performance. The software DisMod-MR 2.1, a meta-regression tool, is used for simultaneous estimates of incidence, prevalence, remission, disability, and also mortality attributable to risk factors, such as physical inactivity ${ }^{13}$. Modeling details can be found in the literature ${ }^{11-13}$.

The present study used the Summary Exposure Value (SEV - equation 1) concept. The SEV represents the prevalence of a disease weighted by the risk. The SEV scale varies from $0 \%$ to $100 \%$, with $0 \%$ representing no risk of exposure and $100 \%$ representing maximum risk; a decline in SEV represents a reduced exposure, while an increase in SEV suggests the opposite. This measure was standardized by age. Information about physical inactivity in 1990 and 2015, by sex, was estimated. More details of SEV are available ${ }^{13}$. SEV was obtained by the equation 1 :

$$
\text { Equation 1: } S E V=\frac{\sum_{i=1}^{n} P r_{i} R R_{i}-1}{R R_{\text {max }}-1}
$$

Where:

$\operatorname{Pr}_{\mathrm{i}}$ is the prevalence of the risk factor,

$\mathrm{RR}_{\mathrm{i}}$ is the relative risk, and 
$\mathrm{RR}_{\text {max }}$ is the observed maximum relative risk (between categories).

The study presents the SEV values for physical inactivity in 1990 and 2015, with 95\% uncertainty intervals (95\%UI), according to sex.

The population-attributable fraction $(\mathrm{PAF})$ of death by ischemic heart disease due to physical inactivity was estimated ${ }^{19}$ using the following equation:

$$
\text { Equation 2: } P A F=\frac{\sum_{i=1}^{\mathrm{n}} P_{i}\left(R R_{i}-1\right)}{\sum_{i=1}^{n} P_{i}\left(R R_{i}-1\right)+1}
$$

Where:

$\mathrm{RR}_{\mathrm{i}}$ is the relative risk for exposure level $\mathrm{i}$,

$\mathrm{P}_{\mathrm{i}}$ is the proportion of the population in that exposure category, and

$\mathrm{n}$ is the number of exposure categories.

A systematic review of relevant epidemiological literature was conducted for the PAF estimates reported ${ }^{20}$. Due to considerable heterogeneity in the literature regarding physical activity metrics and the domain(s) covered, a methodologically intensive strategy was required to standardize the relative risk units to match those of the exposures ${ }^{20}$. More details about this analysis can be found in the literature ${ }^{11}$.

All calculations performed in GBD are repeated 1,000 times; these iterations are known as "draws". Each draw takes a value from data distributions that reflect the sampling and non-sampling error of data inputs, as well as model uncertainty. All resulting estimates are presented with $95 \%$ uncertainty intervals (95\%UI). The UI was defined by the 25th and 975th values of the 1,000 draws $^{11-13}$.

The mortality rate standardized by age, the number of deaths due to ischemic heart disease attributable to physical inactivity, and the percent change information from 1990 to 2015 were estimated following the GBD study methodology. Based on this information, the standardized mortality rate due to ischemic heart disease attributable to physical inactivity in Brazil was compared with that from other high-, middle- and low-income countries. The countries of each category are defined by World Bank criteria and they have been grouped for this study ${ }^{21}$.

\section{RESULTS}

The Brazilian population was found to have a risk of exposure to physical inactivity varying between $70.4 \%$ for men and $75.7 \%$ for women in the year of 1990 . This risk of exposure was similar in 2015. In 1990 and 2015, for both men and women, the risk of exposure to physical inactivity was higher in Brazil than around the world (Figure 1).

In men, the mortality rate due to ischemic heart disease attributable to physical inactivity decreased from 1990 to 2015, approximately, 24\% and 45\% around the world and in Brazil, respectively. In women, this decrease was $31 \%$ around the world and $44 \%$ in Brazil. Although this decreased mortality was more pronounced in Brazil compared to global rates, both in 1990 and 2015 these rates were higher in Brazil than around the world (Table 1; Figure 2).

When analyzing the mortality rate due to ischemic heart disease attributed to physical inactivity in the Brazilian states, it can be observed that in men and women the greatest reductions (1990-2015) occurred in the states of the South and Southeast. In men, the lowest decrease in the mortality rate was observed in the state of Paraíba (-4.72\%), where the mortality rate was higher in 2015. In women, this decrease was lower in the state of Maranhão (-12.06\%), where the mortality rate was higher in 2015 (Table 1). 


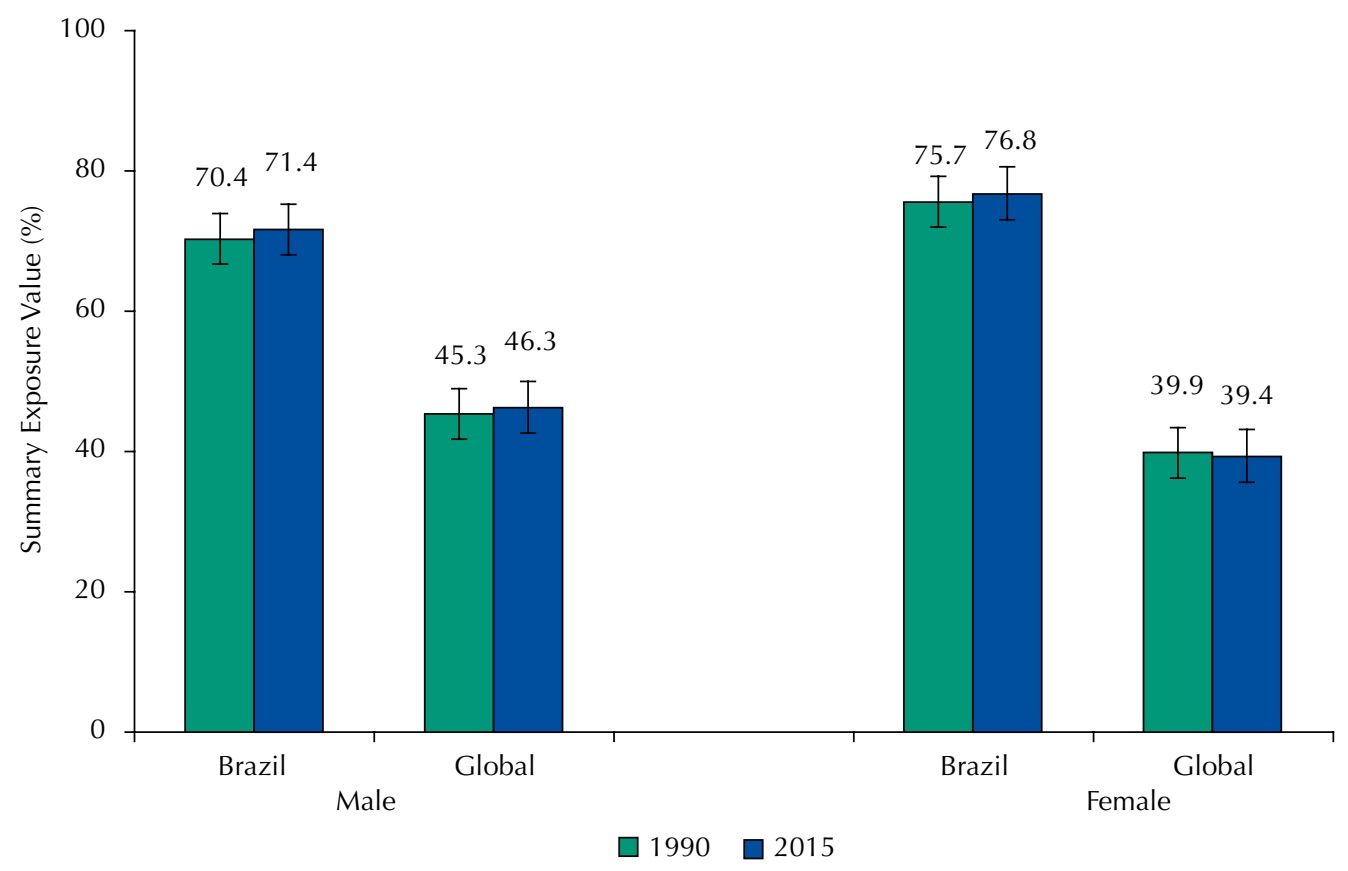

Figure 1. Synthesis of risk exposure (SEV) standardized by age for physical inactivity from 1990 to 2015 in Brazil and the world according to sex.

Table 1. Age-standardized death rate due to ischemic heart disease attributable to physical inactivity in Brazil and worldwide (1990-2015).

\begin{tabular}{|c|c|c|c|c|c|c|c|c|c|c|}
\hline \multirow{4}{*}{ Place } & \multicolumn{5}{|c|}{ Age-standardized death rates (per 100,000 ) } & \multicolumn{5}{|c|}{ Age-standardized death rates (per 100,000 ) } \\
\hline & \multicolumn{4}{|c|}{ Male } & \multirow{3}{*}{$\begin{array}{l}\text { \% change } \\
(1990-2015)\end{array}$} & \multicolumn{4}{|c|}{ Female } & \multirow{3}{*}{$\begin{array}{c}\text { \% change } \\
(1990-2015)\end{array}$} \\
\hline & \multicolumn{2}{|r|}{1990} & \multicolumn{2}{|r|}{2015} & & \multicolumn{2}{|r|}{1990} & \multicolumn{2}{|r|}{2015} & \\
\hline & Rate & $95 \%$ UI & Rate & 95\% UI & & Rate & 95\% UI & Rate & $95 \%$ UI & \\
\hline Global & 23.31 & $15.65-31.43$ & 17.88 & $12.22-24.01$ & -23.96 & 14.25 & $9.42-19.35$ & 9.78 & $6.35-13.27$ & -31.06 \\
\hline Brazil & 38.85 & $28.94-48.72$ & 22.40 & $16.69-28.21$ & -42.99 & 25.24 & $18.93-31.70$ & 13.91 & $10.36-17.42$ & -44.23 \\
\hline Acre & 36.04 & $27.02-45.68$ & 22.08 & $15.80-28.90$ & -39.28 & 22.35 & $16.55-28.84$ & 13.47 & 9.39-18.26 & -39.17 \\
\hline Alagoas & 34.37 & $25.01-43.78$ & 26.51 & $19.01-34.52$ & -23.89 & 26.02 & $18.65-32.97$ & 17.29 & $12.16-23.06$ & -33.09 \\
\hline Amapá & 27.76 & $20.57-35.62$ & 20.22 & 13.50-28.68 & -27.98 & 19.39 & $13.81-25.28$ & 12.32 & $8.27-17.21$ & -36.47 \\
\hline Amazonas & 30.84 & $22.98-39.57$ & 19.13 & $13.52-25.75$ & -36.80 & 22.99 & $17.45-29.31$ & 11.86 & $8.38-15.69$ & -48.27 \\
\hline Bahia & 31.29 & $22.64-40.31$ & 22.67 & $16.42-29.99$ & -26.51 & 23.03 & $16.74-29.40$ & 15.37 & $11.08-20.62$ & -33.82 \\
\hline Ceará & 29.75 & $21.23-38.33$ & 26.49 & $18.70-35.81$ & -10.74 & 21.11 & $15.71-27.34$ & 15.02 & 10.61-20.09 & -28.20 \\
\hline Distrito Federal & 29.84 & $21.62-38.41$ & 15.26 & 11.03-20.19 & -48.74 & 19.22 & $13.81-24.57$ & 8.40 & $6.02-10.87$ & -56.78 \\
\hline Espírito Santo & 36.24 & $26.15-46.92$ & 21.20 & 15.19-28.10 & -41.96 & 22.42 & $16.10-28.67$ & 12.33 & $8.61-16.46$ & -44.45 \\
\hline Goiás & 33.16 & $24.34-42.36$ & 22.95 & $16.57-29.82$ & -30.02 & 24.58 & $18.48-30.88$ & 15.28 & $11.04-19.73$ & -37.11 \\
\hline Maranhão & 48.39 & $34.30-64.25$ & 30.01 & $20.26-42.44$ & -37.97 & 20.99 & $15.10-27.67$ & 18.42 & $12.46-26.12$ & -12.06 \\
\hline Mato Grosso & 42.67 & $31.66-54.04$ & 24.09 & $17.11-31.21$ & -43.52 & 31.12 & $22.77-39.50$ & 15.53 & 10.83-20.36 & -50.32 \\
\hline Mato Grosso do Sul & 36.97 & $26.61-48.39$ & 24.61 & $17.03-32.84$ & -33.15 & 25.57 & $18.27-32.72$ & 13.81 & 9.68-18.09 & -45.76 \\
\hline Minas Gerais & 38.16 & $27.40-48.18$ & 19.35 & $13.53-25.22$ & -49.16 & 24.98 & $18.21-32.21$ & 12.17 & $8.75-15.83$ & -51.44 \\
\hline Paraná & 39.23 & $28.44-50.59$ & 21.90 & 15.92-28.95 & -44.21 & 27.84 & $20.38-35.31$ & 13.94 & $9.84-18.42$ & -49.38 \\
\hline Paraíba & 34.31 & $25.47-43.55$ & 32.60 & $23.25-42.71$ & -4.72 & 24.09 & $17.59-30.78$ & 17.97 & $12.42-24.17$ & -25.79 \\
\hline Pará & 32.76 & $23.96-42.18$ & 23.24 & $15.94-31.56$ & -29.08 & 22.97 & $16.73-29.40$ & 14.30 & $9.94-19.36$ & -37.39 \\
\hline Pernambuco & 36.67 & $27.28-46.97$ & 27.94 & $19.66-36.68$ & -23.08 & 24.71 & $17.87-31.34$ & 16.82 & $11.69-22.46$ & -31.99 \\
\hline Piauí & 31.85 & $23.16-40.92$ & 27.42 & $19.75-36.89$ & -13.96 & 20.94 & $15.36-26.93$ & 15.92 & $11.25-21.28$ & -23.71 \\
\hline Rio de Janeiro & 50.98 & $37.83-65.19$ & 25.18 & $17.44-33.56$ & -50.77 & 29.98 & $22.22-37.62$ & 14.87 & $10.60-19.28$ & -50.85 \\
\hline Rio Grande do Norte & 28.52 & $20.22-36.48$ & 23.93 & $17.15-31.87$ & -16.21 & 19.46 & $14.56-24.82$ & 13.89 & $9.75-18.29$ & -28.91 \\
\hline Rio Grande do Sul & 42.83 & $30.78-55.47$ & 20.54 & $14.24-27.30$ & -52.05 & 25.74 & $18.94-32.53$ & 13.14 & $9.20-17.76$ & -48.74 \\
\hline Rondônia & 44.23 & $32.99-56.28$ & 25.75 & $18.73-33.47$ & -41.77 & 30.92 & $23.43-38.95$ & 16.31 & $11.63-21.68$ & -47.86 \\
\hline Roraima & 32.76 & $24.20-41.41$ & 19.71 & $14.47-25.93$ & -39.37 & 20.03 & $14.81-25.58$ & 11.02 & $7.95-14.40$ & -44.67 \\
\hline Santa Catarina & 37.81 & $26.91-49.09$ & 19.92 & $13.82-26.86$ & -47.13 & 25.49 & $18.58-32.50$ & 12.71 & $8.91-16.79$ & -50.01 \\
\hline Sergipe & 27.83 & $20.47-36.49$ & 21.11 & $15.01-28.28$ & -24.51 & 19.81 & $14.30-25.61$ & 13.82 & $9.61-18.55$ & -30.32 \\
\hline São Paulo & 41.43 & $30.41-52.67$ & 20.11 & $14.28-26.37$ & -51.71 & 26.24 & $19.11-33.35$ & 12.74 & $9.03-16.63$ & -51.61 \\
\hline Tocantins & 30.62 & $21.34-41.30$ & 25.78 & $17.27-34.90$ & -15.18 & 22.66 & $15.49-31.16$ & 16.28 & $11.18-22.31$ & -28.27 \\
\hline
\end{tabular}

UI: uncertainty intervals 


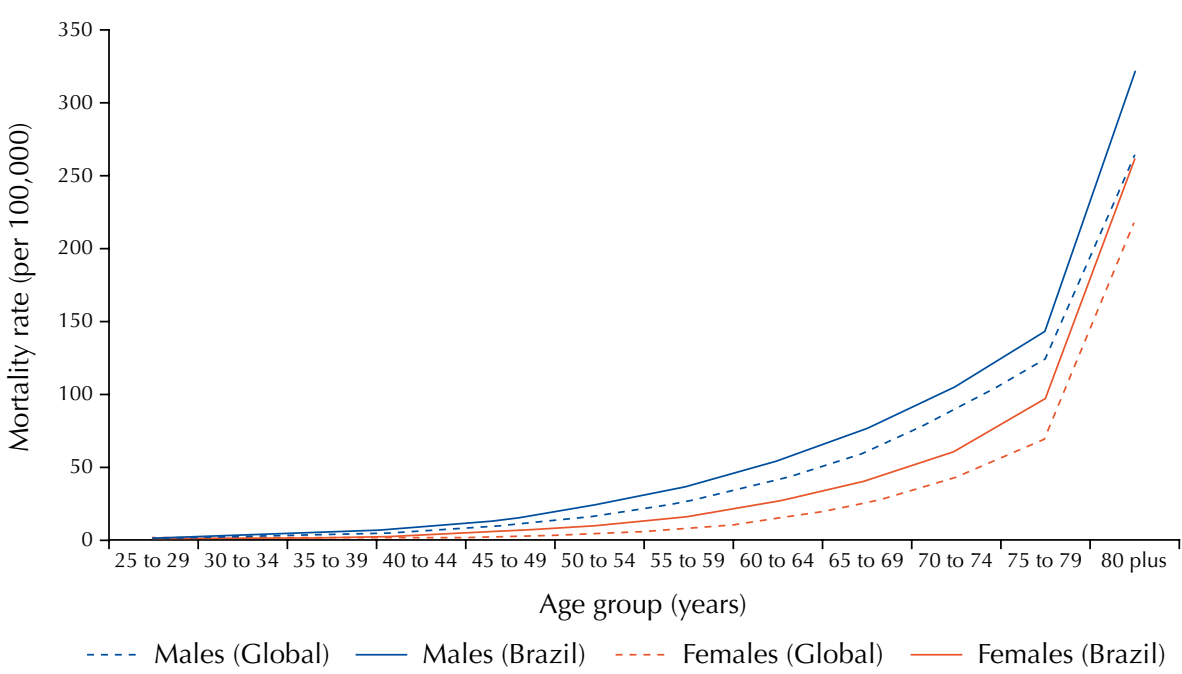

Figure 2. Global mortality rate and mortality rate in Brazil due to ischemic heart disease attributable to physical inactivity according to sex and age in 2015.

Table 2. Total number of deaths due to ischemic heart disease attributable to physical inactivity and population-attributable fraction in Brazil and worldwide according to age group (2015).

\begin{tabular}{|c|c|c|c|c|c|c|c|c|}
\hline \multirow{3}{*}{ Age group } & \multicolumn{8}{|c|}{ Mortality due to ischemic heart disease attributable to physical inactivity (2015) } \\
\hline & \multicolumn{2}{|c|}{ Male (Global) } & \multicolumn{2}{|c|}{ Female (Global) } & \multicolumn{2}{|c|}{ Male (Brazil) } & \multicolumn{2}{|c|}{ Female (Brazil) } \\
\hline & $\begin{array}{l}\text { Number } \\
\text { of deaths }\end{array}$ & $\begin{array}{c}\text { PAF: } \\
\%(95 \% \text { UI) }\end{array}$ & $\begin{array}{l}\text { Number } \\
\text { of deaths }\end{array}$ & $\begin{array}{c}\text { PAF: } \\
\%(95 \% \text { UI) }\end{array}$ & $\begin{array}{l}\text { Number } \\
\text { of deaths }\end{array}$ & $\begin{array}{c}\text { PAF: } \\
\%(95 \% \text { UI) }\end{array}$ & $\begin{array}{l}\text { Number } \\
\text { of deaths }\end{array}$ & $\begin{array}{c}\text { PAF: } \\
\%(95 \% \text { UI })\end{array}$ \\
\hline All ages & 515,021 & $10.6(7.1-14.2)$ & 343,666 & $8.5(5.6-11.6)$ & 17,018 & $15.8(11.8-19.9)$ & 13,413 & $15.2(11.3-18.9)$ \\
\hline $25-29$ years & 3,804 & $15.9(10.2-21.8)$ & 1,063 & $11.9(7.0-17.1)$ & 92 & $23.3(16.3-30.3)$ & 44 & $27.7(20.5-34.3)$ \\
\hline $30-34$ years & 6,496 & $14.0(8.6-19.4)$ & 1,680 & $10.9(6.2-15.9)$ & 219 & $23.4(16.8-29.7)$ & 96 & $26.2(19.4-32.7)$ \\
\hline $35-39$ years & 9,455 & $12.9(7.9-17.8)$ & 2,310 & $10.1(5.6-14.7)$ & 371 & $22.9(16.8-28.9)$ & 160 & $24.6(18.1-30.8)$ \\
\hline 40-44 years & 15,516 & $12.6(7.9-17.5)$ & 3,735 & $9.8(5.4-14.1)$ & 603 & $22.2(16.2-28.0)$ & 271 & $22.9(16.8-28.8)$ \\
\hline $45-49$ years & 24,394 & $12.2(7.7-16.8)$ & 6,420 & $9.6(5.4-13.7)$ & 948 & $21.0(15.3-26.4)$ & 458 & $21.4(15.6-26.9)$ \\
\hline 50-54 years & 34,134 & $11.4(7.2-15.8)$ & 9,725 & $9.3(5.3-13.3)$ & 1,464 & $19.5(14.2-24.6)$ & 694 & $19.9(14.6-25.2)$ \\
\hline 55-59 years & 45,020 & $11.3(7.2-15.8)$ & 14,060 & $9.0(5.2-12.9)$ & 1,787 & $18.2(13.3-23.0)$ & 874 & $18.8(13.8-23.8)$ \\
\hline 60-64 years & 61,001 & $11.4(7.4-15.5)$ & 23,224 & $8.9(5.3-12.6)$ & 2,043 & $17.4(12.8-21.9)$ & 1,165 & $17.9(13.3-22.6)$ \\
\hline 65-69 years & 59,332 & $11.4(7.6-15.3)$ & 27,909 & $8.9(5.6-12.4)$ & 2,089 & $16.3(12.1-20.6)$ & 1,358 & $16.9(12.7-21.2)$ \\
\hline 70-74 years & 65,143 & $10.4(7.0-14.0)$ & 36,884 & $8.1(5.1-11.3)$ & 1,937 & $15.1(11.3-19.1)$ & 1,443 & $15.6(11.8-19.6)$ \\
\hline 75-79 years & 61,385 & $9.8(6.8-13.1)$ & 43,383 & $8.0(5.2-11.0)$ & 1,841 & $13.8(10.3-17.3)$ & 1,724 & $14.2(10.6-17.8)$ \\
\hline$\geq 80$ years & 129,334 & $9.3(6.6-12.1)$ & 173,267 & $8.5(5.9-11.2)$ & 3,619 & $12.5(9.5-15.5)$ & 5,120 & $12.9(9.8-15.9)$ \\
\hline
\end{tabular}

PAF: Population-attributable fraction, i.e., the contribution of physical inactivity to death for ischemic heart disease; UI: uncertainty intervals

As shown in Table 2, if physical inactivity was eliminated from the world in 2015, the number of deaths due to ischemic heart disease would be decreased by $10.6 \%$ for men and $8.5 \%$ for women. In Brazil, this reduction would be more evident (15.8\% for men and $15.2 \%$ for women). Physical inactivity was found to have an impact on death due to ischemic heart disease, which presented for all analyzed ages.

Figure 3 shows that, in a global comparison, higher rates of mortality due to ischemic heart disease attributable to physical inactivity were reported in Brazil and middle- to low-income countries compared to high-income nations. 


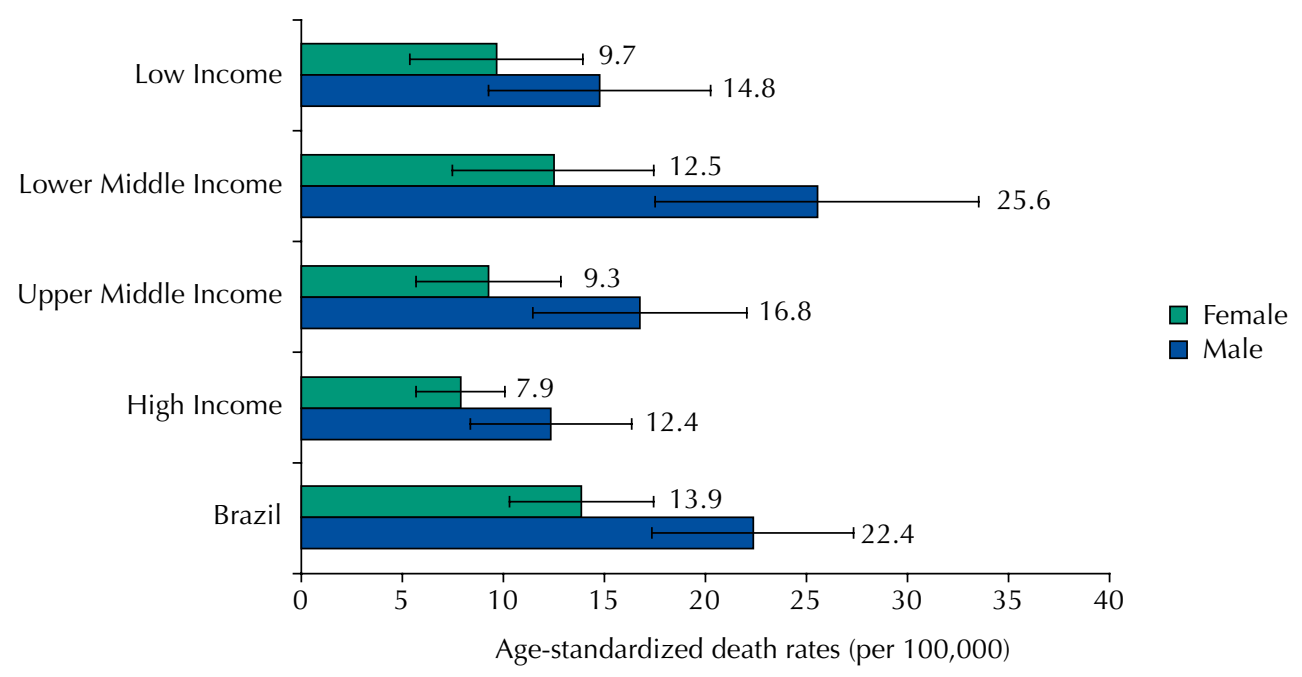

Figure 3. Age-standardized mortality rate due to ischemic heart disease attributable to physical inactivity in Brazil and groups of countries classified by income level as according to World Bank (2015).

\section{DISCUSSION}

The main finding of this study was that physical inactivity led to mortality due to ischemic heart disease in Brazilian adults and older people over the analyzed period (1990 to 2015). The results confirmed that the Brazilian population is more exposed to the risk of physical inactivity than the world population. Also, the mortality rate due to ischemic heart disease attributable to physical inactivity is correspondingly higher in Brazil than other countries around the world, regardless of differences in income level. Also, when analyzing the data of the Brazilian states, we observed that the greatest reductions from 1990 to 2015 in age-standardized death rates were in the states with better socioeconomic conditions.

The results of the present study agree with a meta-analysis of epidemiological studies that focused on physical activity as a primary preventative measure from coronary artery disease ${ }^{7}$. The meta-analysis, consisting of 33 studies, reported that individuals who engaged in the equivalent of 150 minutes/week of moderate-intensity leisure-time physical activity had a $14.0 \%(\mathrm{RR}=0.86,95 \% \mathrm{CI} 0.77-0.96)$ lower risk of coronary heart disease than those reporting no leisure-time physical activity. In addition, the meta-analysis found that those who 300 minutes/week of moderate-intensity leisure-time physical activity had a $20.0 \%$ ( $\mathrm{RR}=0.80,95 \% \mathrm{CI} 0.74-0.88)$ lower risk of coronary heart disease. The most surprising result of the meta-analysis was that individuals who were physically active at levels lower than the minimum amount recommended ( $<150$ minutes/week) had a risk of coronary heart disease significantly lower than those reporting no leisure-time physical activity. This result supports the assertion that some physical activity is better than none?

Another meta-analysis using prospective cohort studies investigated both leisure-time physical activity and occupational physical activity ${ }^{8}$ and the associated risk of developing coronary heart disease through follow-up studies. The authors reported that men $(\mathrm{RR}=0.76$, 95\% CI $0.70-0.82)$ and women $(\mathrm{RR}=0.73,95 \% \mathrm{CI} 0.68-0.78)$ who met the physical activity guideline for health had a lower risk of developing cardiovascular disease than those with low levels of leisure-time physical activity. Similar results were found for occupational physical activity; people with a moderate level of occupational physical activity had lower risks of developing cardiovascular disease ${ }^{8}$. These findings support the results of the present study, which not only analyzed physical activity in the leisure period but in all domains (leisure, commuting, occupational, at home).

The risk of exposure of the Brazilian population to physical inactivity did not change from 1990 to 2015. However, the age-standardized death rates by ischemic heart disease attributable to physical inactivity decreased from 1990 to 2015. One explanation for this is that mortality 
by ischemic heart disease in Brazil has declined in those 25 years ${ }^{6,22}$. This decrease results from the improvement of health services in Brazil ${ }^{22}$ and the control of other risk factors for cardiovascular diseases, such as smoking ${ }^{17}$.

A disconcerting fact of the present study is that age-standardized death rates due to ischemic heart disease attributable to physical inactivity were higher in Brazil than worldwide for both sexes. This result suggests that more effort is required to promote physical activity in Brazil. The National Policy for Health Promotion was created in 2006 and represented a milestone in the policy of promoting physical activity in Brazil. Since the publication of this document, other strategies to promote physical activity have been launched, such as the National Plan of Physical Practices and Physical Activity and the Family Health Support Nucleus ${ }^{23,24}$. These initiatives provided greater awareness and access of the population to physical activity. However, few studies evaluating the impact, reach, and effectiveness of these policies can be found in the literature ${ }^{24,25}$. This limits the possibility for reformulation and for the implementation of new strategies to bring more effective results to the population in Brazil, a country with a continental dimension. Therefore, a frequent monitoring of these policies is necessary to reduce and combat the epidemic of physical inactivity.

One fact that may explain the high risk of exposure of the Brazilian population to physical inactivity and, consequently, the high number of deaths due to ischemic heart disease in adulthood is the high number of children and adolescents in Brazil who do not meet recommendations for physical activity. A survey monitoring physical activity in Brazilian youth found that almost $60.0 \%$ of individuals did not meet physical activity recommendations ${ }^{26}$. Therefore, the findings of this study may suggest that the promotion of physical activity should begin with younger age groups, especially for the prevention of NCD.

The Brazilian states with better socioeconomic conditions presented greater reductions (1990-2015) in mortality rates due to ischemic heart disease attributed to physical inactivity. This finding may reflect the lower prevalence of physical inactivity, obesity, and other risk factors in these regions compared to those with worse socioeconomic conditions, as evidenced by the VIGITEL ${ }^{3}$. An explanation for these discrepancies is the process of epidemiological transition in which Brazil is inserted. The more economically developed regions may already have better controlled NCD by means of risk factor control actions ${ }^{3}$.

This study provides important information about the impact of low levels of physical activity on mortality due to ischemic heart disease. The literature indicates that physical inactivity was responsible for $6.0 \%$ of coronary artery disease cases worldwide and $9.0 \%$ of premature mortality by any cause ${ }^{1}$. The findings of this study present the direct relationship between low levels of physical activity and mortality due to cardiovascular disease over time (1990-2015), demonstrating the case of Brazil, where physical inactivity is responsible for $15.0 \%$ of deaths due to ischemic heart disease.

This study analyzed all domains of physical activity (leisure, commuting, occupational, at home) to understand the benefits to peoples health and to inform the prevention of cardiovascular diseases. Furthermore, this study compared the mortality rate in Brazil with global estimates, considering national income levels, detailing the problem of low levels of physical activity across world populations. Finally, this study used the SEV measure to demonstrate the risk of exposure to physical inactivity in Brazil and around the world.

The first limitation of this study was the investigation of only one cardiovascular disease, which did not allow inferences regarding the impact of physical inactivity on diseases other than ischemic heart disease. Second, the effect of physical inactivity on other diseases such as cancer and diabetes has not been investigated. Third, the findings presented herein were based on surveys that estimate physical activity by questionnaires, which are considered subjective measures of physical activity and associated with measurement bias. Four, the non-stratification of physical activity by domains is another limitation. Finally, the estimates 
of physical activity made for the older population should be interpreted with caution, because the questionnaires used may not accurately measure physical activity in this population.

In this study, we decided to treat the terms 'physical inactivity' and 'low levels of physical activity' as synonyms to convey the message more clearly to the reader. The risk classification used was < 600 METS-min/week, as recommended by the literature ${ }^{18}$.

We can conclude that, over 25 years, the risk of exposure of the Brazilian population to physical inactivity has not changed and is high compared to the rest of the world. Physical inactivity is responsible for a significant number of deaths due to ischemic heart disease in Brazil and approximately $15.0 \%$ of these deaths could be avoided if people met the recommendations for physical activity. The mortality rate due to ischemic heart disease attributable to physical inactivity is higher in Brazil than in other countries, regardless of income level. The Brazilian states with better socioeconomic conditions presented greater reductions (1990-2015) in mortality rates due to ischemic heart disease attributed to physical inactivity.

\section{REFERENCES}

1. Lee IM, Shiroma EJ, Lobelo F, Puska P, Blair SN, Katzmarzyk PT; Lancet Physical Activity Series Working Group. Effect of physical inactivity on major non-communicable diseases worldwide: an analysis of burden of disease and life expectancy. Lancet. 2012;380(9838):219-29. https://doi.org/10.1016/S0140-6736(12)61031-9

2. Kohl HW 3rd, Craig CL, Lambert EV, Inoue S, Alkandari JR, Leetongin G, et al. The pandemic of physical inactivity: global action for public health. Lancet. 2012;380(9838):294-305. https://doi.org/10.1016/S0140-6736(12)60898-8

3. Malta DC, Stopa SR, Iser BPM, Bernal RTI, Claro RM, Nardi ACF, et al. Risk and protective factors for chronic diseases by telephone survey in capitals of Brazil, Vigitel 2014. Rev Bras Epidemiol. 2015;18 Suppl 2:238-55. https://doi.org/10.1590/1980-5497201500060021

4. Mansoubi M, Pearson N, Biddle SJ, Clemes S. The relationship between sedentary behaviour and physical activity in adults: a systematic review. Prev Med. 2014;69:28-35. https://doi.org/10.1016/j.ypmed.2014.08.028

5. Salvo D, Sarmiento OL, Reis RS, Hino AAF, Bolivar MA, Lemoine PD, Gonçalves PB, Pratt M. Where Latin Americans are physically active, and why does it matter? Findings from the IPENadult study in Bogota, Colombia; Cuernavaca, Mexico; and Curitiba, Brazil. Prev Med. 2017;103 Suppl:S27-33. https://doi.org/10.1016/j.ypmed.2016.09.007

6. Schmidt MI, Duncan BB, Azevedo e Silva G, Menezes AM, Monteiro CA, Barreto SM, et al. Chronic non-communicable diseases in Brazil: burden and current challenges. Lancet. 2011;377(9781):1949-61. https://doi.org/10.1016/S0140-6736(11)60135-9

7. Sattelmair J, Pertman J, Ding EL, Kohl HW 3rd, Haskell W, Lee IM. Dose response between physical activity and risk of coronary heart disease: a meta-analysis. Circulation. 2011;124(7):789-95. https://doi.org/10.1161/CIRCULATIONAHA.110.010710

8. Li J, Siegrist J. Physical activity and risk of cardiovascular disease: a meta-analysis of prospective cohort studies. Int J Environ Res Public Health. 2012;9(2):391-407. https://doi.org/10.3390/ijerph9020391

9. Duncan BB, Schmidt MI, Cousin E, Moradi-Lakeh M, Passos VMA, França EB, et al. The burden of diabetes and hyperglycemia in Brazil-past and present: findings from the Global Burden of Disease Study 2015. Diabetol Metab Syndr. 2017;9:18. https://doi.org/10.1186/s13098-017-0216-2

10. Ministério da Saúde (BR), Secretaria de Vigilância em Saúde, Departamento de Análise de Situação em Saúde. Plano de ações estratégicas para o enfrentamento das doenças crônicas não transmissíveis (DCNT) no Brasil 2011-2022. Brasília (DF); 2011 [cited 2016 Dec 10]. Available from: http://bvsms.saude.gov.br/bvs/publicacoes/plano_acoes_enfrent_dcnt_2011.pdf

11. GBD 2015 Disease and Injury Incidence and Prevalence Collaborators. Global, regional, and national incidence, prevalence, and years lived with disability for 310 diseases and injuries, 1990-2015: a systematic analysis for the Global Burden of Disease Study 2015. Lancet. 2016;388(10053):1545-602. https://doi.orh/10.1016/S0140-6736(16)31678-6 
12. GBD 2015 Mortality and Causes of Death Collaborators. Global, regional, and national life expectancy, all-cause mortality, and cause-specific mortality for 249 causes of death, 1980-2015: a systematic analysis for the Global Burden of Disease Study 2015. Lancet. 2016;388(10053):1459-544. https://doi.org/10.1016/S0140-6736(16)31012-1

13. GBD 2015 Risk Factors Collaborators. Global, regional, and national comparative risk assessment of 79 behavioural, environmental and occupational, and metabolic risks or clusters of risks, 1990-2015: a systematic analysis for the Global Burden of Disease Study 2015. Lancet. 2016;388(10053):1659-724. https://doi.org/10.1016/S0140-6736(16)31679-8

14. Souza MFM, França EB, Cavalcante A. Burden of disease and health situation analysis: results of the Global Burden of Disease (GBD) Brazil network. Rev Bras Epidemiol. 2017;20 Suppl 1:1-3. https://doi.org/10.1590/1980-5497201700050001

15. Moran AE, Forouzanfar MH, Roth GA, Mensah GA, Ezzati M, Flaxman A, et al. The global burden of ischemic heart disease in 1990 and 2010: The Global Burden of Disease 2010 study. Circulation. 2014;129(14):1493-501. https://doi.org/10.1161/CIRCULATIONAHA.113.004046

16. Roth GA, Johnson C, Abajobir A, Abd-Allah F, Abera SF, Abyu G, et al. Global, Regional, and National Burden of Cardiovascular Diseases for 10 Causes, 1990 to 2015. J Am Coll Cardiol. 2017;70(1):1-25. https://doi.org/10.1016/j.jacc.2017.04.052

17. Malta DC, Felisbino-Mendes MS, Machado ÍE, Passos VMA, Abreu DMX, Ishitani LH, et al. Risk factors related to the global burden of disease in Brazil and its Federated Units, 2015. Rev Bras Epidemiol. 2017;20 Suppl 1:217-32. https://doi.org/10.1590/1980-5497201700050018

18. World Health Organization, Prevention of Noncommunicable Diseases Department. Global Physical Activity Questionnaire (GPAQ): analysis guide. Geneva: WHO; 2013 [cited 2018 Feb 13]. Available from: http://www.who.int/ncds/surveillance/steps/resources/GPAQ_Analysis_Guide.pdf

19. Miettinen OS. Proportion of disease caused or prevented by a given exposure, trait or intervention. Am J Epidemiol. 1974;99(5):325-32. https://doi.org/10.1093/oxfordjournals.aje.a121617

20. Kyu HH, Bachman VF, Alexander LT, Mumford JE, Afshin A, Estep K, et al. Physical activity and risk of breast cancer, colon cancer, diabetes, ischemic heart disease, and ischemic stroke events: systematic review and dose-response meta-analysis for the Global Burden of Disease Study 2013. BMJ. 2016;354:i3857. https://doi.org/10.1136/bmj.i3857

21. World Bank. Countries and economies. Washington (DC); c2016 [cited 2016 Dec 10]. Available from: http://data.worldbank.org/country

22. Brant LCC, Nascimento BR, Passos VMA, Duncan BB, Bensenõr IJM, Malta DC, et al. Variations and particularities in cardiovascular disease mortality in Brazil and Brazilian states in 1990 and 2015: estimates from the Global Burden of Disease. Rev Bras Epidemiol. 2017;20 Suppl 1:16-28. https://doi.org/10.1590/1980-5497201700050010

23. Malta DC, Castro AM, Gosch CS, Cruz DKA, Bressan A, Nogueira JD, et al. A Política Nacional de Promoção da Saúde e a agenda da atividade física no contexto do SUS. Epidemiol Serv Saude. 2009;18(1):79-86. https://doi.org/10.5123/S1679-49742009000100008

24. Fernandes AP, Andrade ACS, Ramos CGC, Friche AAL, Dias MAS, Xavier CC, et al. Leisure-time physical activity in the vicinity of Academias da Cidade Program in Belo Horizonte, Minas Gerais State, Brazil: the impact of a health promotion program on the community. Cad Saude Publica. 2015;31 Suppl 1:195-207. https://doi.org/10.1590/0102-311X00104514

25. Simões EJ, Hallal PC, Siqueira FV, Schmaltz C, Menor D, Malta DC, et al. Effectiveness of a scaled up physical activity intervention in Brazil: a natural experiment. Prev Med. 2017;103 Suppl:S66-72. https://doi.org/10.1016/j.ypmed.2016.09.032

26. Nardo Jr N, Silva DAS, Ferrari GLM, Petroski EL, Pacheco RL, Martins PC, et al. Results From Brazil's 2016 Report Card on Physical Activity for Children and Youth. J Phys Act Health. 2016;13(11 Suppl 2):S104-9. https://doi.org/10.1123/jpah.2016-0398

Funding: Bill \& Melinda Gates Foundation (GBD Global) and Ministry of Health (GBD 2015 Brazil-states), through the National Health Fund (Process 25000192049/2014-14).

Authors' Contribution: Design and planning of the study: DASS, DCM, MFMS, MN. Collection, analysis, and interpretation of the data: DASS, DCM, MFMS, MN. Preparation or review of the study: DASS. Approval of the final version: DASS, DCM, MFMS, MN. Public responsibility for the content of the article: DASS, DCM, MFMS, MN.

Conflict of Interest: The authors declare no conflict of interest. 